\title{
Lung Distensibility and Airway Function in Asthmatic Children
}

\author{
RICHARD KRAEMER AND FERNAND GEUBELLE \\ Pulmonary Function Laboratories, Departments of Pediatrics, University of Berne [R.K.], Switzerland, and \\ Liege [F.G.], Belgium
}

\begin{abstract}
Lung distensibility and airway mechanics were evaluated in 24 asthmatic children and adolescents, ages between 7 and 21 years, by quasi-static pressurevolume curves and by the static recoil-lung conductance relationship. The measurements were obtained by the stepwise inflation technique and the pressure-volume curves were analyzed by a new sigmoid exponential curve-fitting model of the form: $V_{L}=V_{m}+\left[V_{M} /\left(1+b e^{-K \cdot P_{s L}}\right)\right]$, where $V_{L}$ is lung volume, $P_{s t}$ is static recoil pressure, $V_{M}$ and $V_{m}$ are the upper and lower asymptotes, and $K$ and $b$ are shape constants. The shape constant $K$ serves as index for lung distensibility, whereas the slope of $\theta$ of the static recoillung conductance plot represents the flow-resistive behavior of the airways. The combined evaluation of these two parameters $(K$ and $\theta)$ shows that some asthmatic children have a very high lung distensibility and normal airway function, whereas others have nearly normal lung elasticity but grossly reduced airway distensibility. Sigmoid exponential analysis of static pressure-volume curves and an evaluation of the static recoil-lung conductance relationship in asthmatic children enable a distinction of these two types of functional derangements. Increased pulmonary distensibility consistent with an increase of alveolar air space seems to indicate an involvement of tissue elements. In contrast, decreased airway distensibility indicates a defect in the conducting airways. Sympathomimetics not only have a positive effect on airway mechanics, but seem to increase lung distensibility both in patients with hyperinflation and to an even greater degree in patients whose lungs are already too compliant. (Pediatr Res 18:1154$1159,1984)$
\end{abstract}

\section{Abbreviations}

$\mathrm{PV}$, pressure volume

$C_{\mathrm{dyn}}$, dynamic compliance

$\mathrm{FiO}_{2}$, fraction of inspired oxygen

FRC, functional residual capacity

$G_{L}$, lung conductance

$P_{b}$, barometric pressure

$P_{s t L_{2}}$, static recoil pressure

$P_{s t L}-G_{L}$, static recoil-lung conductance

$R_{L}$, total lung resistance

$R V$, residual volume

SD-S, standard deviation seore

TG, trapped gas

Received November 30, 1983; May 10, 1984.

Requests for reprints should be addressed to R. Kracmer. M.D., Department of Pediatrics, University of Berne, Inselspital CH-3010 Berne, Switzerland.

This study was supported by Grants from the University of Liege (Belgium) and the Stiftung zur Foerderung wissenschaftlicher Forschung an der Universitaet Bern (Switzerland)

\author{
TGV, thoracic gas volume \\ TLC, total lung capacity \\ VC, vital capacity \\ $V_{L}$, lung volume
}

One of the epidemiological aspects of childhood asthma is the question of the reversibility of functional abnormalities (23) and in particular how this factor relates to the potential to develop chronic obstructive lung disease. In this paper, we describe some functional features which may serve as indicators of later lung damage.

Airflow limitation, the common functional characteristic of airway disease, can be due to a decrease in driving pressure (pulmonary elastic recoil), or intrinsic airway narrowing $(4,5$, $17,18,24-27,34)$. Studies in adults have related the PV characteristics of the lung to structural alterations $(17,18,30,37)$. However, recent studies have shown that only the exponential analysis of PV curves accurately define PV characteristics in different age groups and groups with different functional derangements $(7,8,17,18,20,29,31-33,35,36)$. An exponential analysis of PV curves yields a shape constant $K$, reflecting pulmonary distensibility $(6,7,17,18)$ which is independent of sex and lung size, and is additionally insensitive to differences in measurement techniques $(7,20,36)$. However, the relationship between the exponential shape constant $K$ and furthermore $b$, the intercept defining the position of the PV curve in respect to the pressure axis on the one hand, and age and growth on the other hand, are not known. In addition, it is essential not only to describe the shape of the curve, but also to determine its position in relation to the pressure and volume axis. Therefore, additional parameters like the asymptotes indicating the lower and upper limits of lung volume are required. Data of healthy children, evaluated by a new sigmoid exponential function, have recently been published (24).

The dynamic behavior of the airways, and hence an evaluation of the state of lower airways, is best represented by the relationship between airway dimensions and airway distending forces. Lung conductance varies with the state of inflation as a function of the elastic forces of the lungs, which provide forces to distend the airways (4). In addition, factors reflecting changes in the airway wall and lumen itself have to be considered (reduced bronchiai distensibiiity). Therefore, the contribution of intrinsic narrowing to the airflow limitation can be approximated by plotting lung conductance $\left(G_{l}\right)$, measured at low flows, against static recoil pressure $\left(P_{s t} t\right)$.

In the present study we measured PV curves in symptom-free asthmatic children and were interested in whether, within this apparently clinically homogeneous group of young patients, different functional groups might be detected. Moreover, we wanted 
to know how such functional abnormalities are influenced by $\beta$ 2-agonists.

\section{MATERIALS AND METHODS}

Patients. Twenty-four asthmatic children and adolescents, ages between 7 and 21 years, who were regularly attending the asthma clinic of the University Children's Hospital Liège (Belgium) were selected for this study. All patients were known to have asthma for more than 1 year with episodic dyspnea, positive skin tests, positive RAST results, well documented varying reversible bronchoconstriction (positive response to $\beta$-2-mimetics), bronchial hyperreactivity (histamine challenge test), and positive bronchial challenge test to one or more allergens. All patients were familiar with the lung function technique applied and were evaluated strictly during the symptom-free interval $(9,23)$. Nevertheless, they had mild to severe occult lung function abnormalities.

Lung distensibility was evaluated measuring the quasi-static PV-curves between FRC and approximately 90\% TLC (Fig. 1) using the pressure and volume as input to a computer program designed to fit the data to a sigmoid exponential function of the form (24):

$$
V_{L}=V_{m}+\left[V_{M} /\left(1+b e^{-K \cdot P_{s L L}}\right)\right]
$$

where $V_{L}$ is the lung volume, $P_{s t L}$ is the static recoil pressure, and $V_{M}$ and $V_{m}$ are the upper and lower asymptotes (limit of lung volume). The effect of varying these parameters is shown in Figure 1. A high numerical negative $K$ indicates a very compliant lung, whereas a low $K$ indicates a lung with decreased lung distensibility. The PV curves with high $K$ are high sloped and high curved, especially in the upper lung volume range. In contrast, a decrease of $K$ leads to a decrease of the slope and increases the linearity of the curve. The logarithm of the intercept of this exponential function ( $\ln b$ ) defines the position of the PV curve with respect to the pressure axis in so far as an increase of $\ln b$ means a right-hand shift, a decrease of $\ln b$ a left-hand shift of the curve, respectively (24).

Airway distensibility was evaluated by determination of the slope of the $P_{s t L}-G_{L}$ plot. If high $P_{s t L}$ is needed to increase lung conductance, the distensibility of the airways is low. Consequently, $\theta$, the slope of the $P_{s t L}-G_{L}$ plot is low (Fig. 1). Conversely, if lung conductance is increased by increasing static recoil pressure (as in normal subjects), $\theta$ is high, demonstrating good airway distensibility (5).

Experimental procedure. Lung function tests were performed at least 2 wk after the last acute episode and after cessation of bronchodilating and steroid drugs. FRC was measured by the helium dilution technique in a closed spirometric circuit. At least three measurements were performed and the mean of the two nearest measurements of FRC was calculated. Each measurement was followed by three slow VC maneuvers so that TLC and RV were calculated. TGV at the resting end-expiratory level was measured with the patient seated in an air-conditioned, constant volume, variable pressure whole-body plethysmograph for children (12). Static respiratory efforts against the shutter were performed at low frequency (no panting) and TGV was measured by the Boyle's law technique (11). Lung volume data were expressed in per cent predicted normal, based on the standing height using data collected in healthy subjects from a similar population $(13,15)$. The TG was defined as the difference between TGV (plethysmographically determined) and FRC (determined by helium dilution technique) both expressed in per cent predicted normal.

Transpulmonary pressure was recorded as the difference between mouth and esophageal pressure by the esophageal balloon technique of Milic-Emili et al. (28). The catheter with the balloon adjusted to $P_{b}$ and therefore at almost zero volume (length, 9.5 $\mathrm{cm}$; perimeter, $5 \mathrm{~cm}$; wall thickness, $0.1 \mathrm{~mm}$ ) was connected to a pressure transducer (Elema-Schonander EMT 34). The volume displacement coefficient of the catheter-manometer system was about $0.004 \mathrm{~mm} / \mathrm{cm} \mathrm{H}_{2} \mathrm{O}$. Great care was taken to locate the balloon in the mid to lower one-third of the esophagus, the distance between the nares and the balloon having been estimated from our own published data (14).

$P_{s i L}$, equal to transpulmonary pressure at zero flow points, was obtained in absolute values, i.e. versus $P_{b}$. Air flow was measured by means of a Fleisch pneumotachograph No. 2 and lung volume changes were given by integration of the flow signal. PV curves during inflation between FRC and 90\% TLC were obtained by the so-called "stepwise inflation technique" (24). The child was asked to breathe as regularly as possible (respiratory frequency, $16.7 \pm 1.5 / \mathrm{min}$ ) at different lung volumes during stepwise inflation (Fig. 2). $P_{s t L}$ at the different lung volumes was measured as the mean of the end-expiratory pressure of at least five cycles during quiet breathing. During the stepwise inflation, oxygen was continuously added to the spirographic system in order to keep the inspiratory oxygen concentration $\left(\mathrm{FiO}_{2}\right)$ constant (Beckman analyzer). Changes in helium concentration indicating changes in the calculated FRC due to recruitment of alveolar space was carefully recorded. By this approach, it was possible to follow the variations of FRC and, by addition of the inspiratory capacity to the actual FRC, to get the actual TLC for each step (22). In order to obtain $V_{L}$ in absolute terms, the different inspiratory levels were recalculated on the basis of the greatest

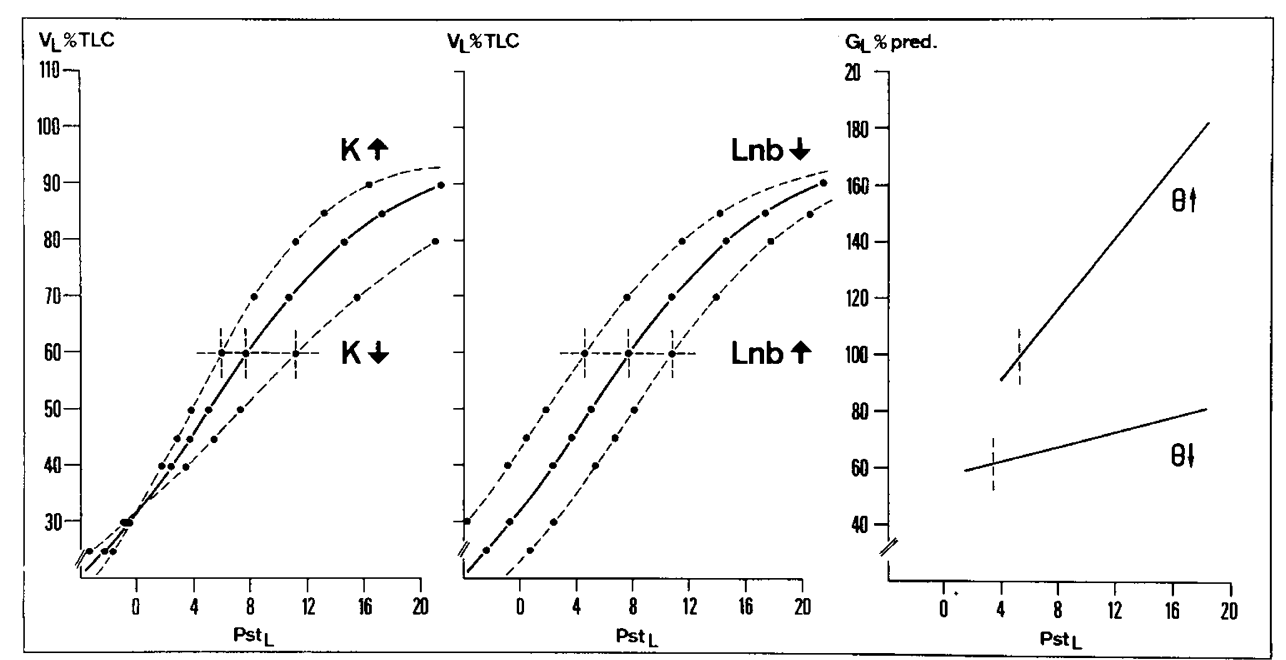

Fig. 1. Evaluation of lung distensibility (left) due to the computation of $K$ from the exponential PV curve-fitting model: $V_{L}=V_{m}+\left[V_{M} /(1+\right.$ $\left.b e^{-K \cdot P_{s t}}\right)$ ]. Middle, influence of $\ln b$ (the natural logarithm of $b$ ) on the PV curve. Right, determination of airway distensibility according to the slope $\theta$ of the $P_{s t L}-G_{L}$ plot (high $\theta: \operatorname{good}$ airway distensibility; low $\theta$ : reduced airway distensibility). 
calculated TLC, reached after complete helium dilution, substracting the corresponding inspiratory capacities. $V_{L}$ was expressed in per cent TLC in order to correct for body (and hence, lung) size. Data were recorded on a multichannel recorder, extracted and punched on diskettes for subsequent computer analysis (DEC PDP 11/03). For each patient, at least two satisfactory sets of inflation PV data were required for analysis. In order to correct the values according the age dependency and

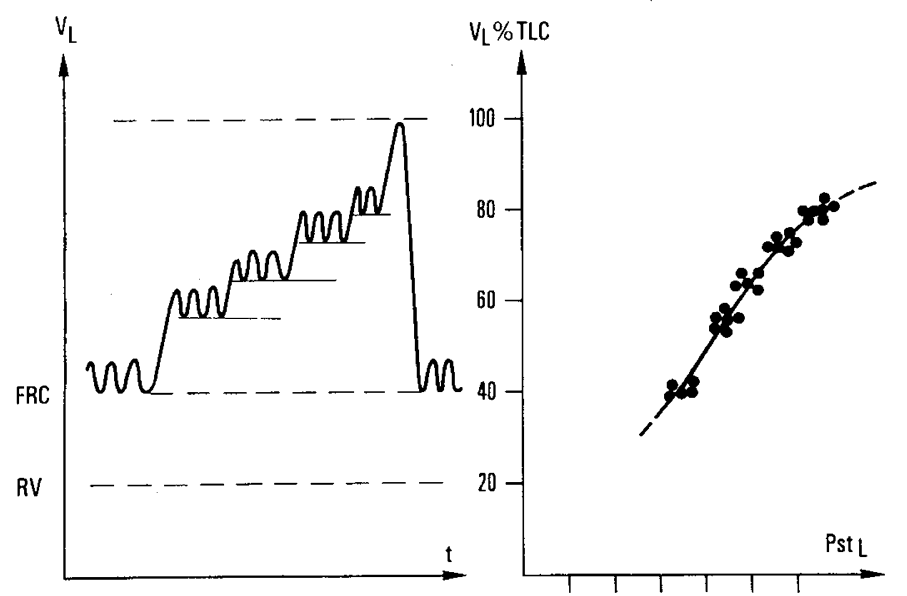

Fig. 2. Respiratory pattern in order to obtain PV data during normal breathing with stepwise inflation from FRC up to $90 \%$ of TLC. logarithmic distribution in healthy children (24), $K$ and $\ln b$ have been expressed in standard deviations (SD-S).

Total pulmonary flow resistance $\left(R_{L}\right)$ was calculated from midtidal esophageal pressure and flow changes during quiet breathing for each inspiratory level (mean of at least five breathing cycles). $G_{L}$ was calculated as reciprocal value of total pulmonary flow resistance and was expressed in per cent predicted according to the values previously worked out in healthy children (15). Dynamic compliance $\left(C_{\mathrm{dyn}}\right)$ during normal frequency breathing was calculated from simultaneous volume and intraesophageal pressure changes at zero flow points between the start and end of the inspiration (14).

Statistical analysis. Correlations were performed by regression analysis and the Spearman rank correlation tests; discriminating analysis of $K$ and $\theta$ was by the Kruskal-Wallis $H$ test.

\section{RESULTS}

Anthropometric data, the measurements of lung volumes (TLC, TGV, FRC, RV), total resistance to the airflow $\left(R_{L}\right)$, and dynamic compliance $\left(C_{\text {dyn }}\right)$ (both measured at FRC and presented in per cent predicted), as well as $K$ and $\theta$ (slope of the $P_{s t L}-G_{L}$ per cent predicted plot) in absolute values are summarized in Table 1. According to functional features, the patients have been divided into three groups, where group I comprises patients with hyperinflation $(\mathrm{TGV}>130 \%$ predicted $=$ mean + 2SD), group II patients with hyperinflation and bronchoconstriction $\left(\mathrm{TGV}>130 \%\right.$ predicted $=$ mean $+2 \mathrm{SD} ; R_{L}>130 \%$ predicted $=$ mean $+2 \mathrm{SD}$ ) and group III patients with broncho-

Table 1. Biometric data, lung volumes and their subdivisions, parameters of lung mechanics as well as the shape constant $K$ and the slope $\theta$ of the 24 asthmatic children investigated*

\begin{tabular}{|c|c|c|c|c|c|c|c|c|}
\hline $\begin{array}{l}\text { Age } \\
(\mathrm{yr})\end{array}$ & $\begin{array}{l}\text { Height } \\
(\mathrm{cm})\end{array}$ & TLC & TGV & $\begin{array}{c}\text { FRC } \\
\text { (\% predicted) }\end{array}$ & $\mathrm{RV}$ & $R_{L}$ & $C_{\mathrm{dyn}}$ & $\begin{array}{cc}K & \theta \\
\left(\mathrm{cm} \mathrm{H}_{2} \mathrm{O}^{-1}\right)\end{array}$ \\
\hline 10.0 & 147 & 115 & 142 & 136 & 131 & 101 & 142 & $-0.3491 \quad 8.55$ \\
\hline 7.6 & 119 & 108 & 142 & 101 & 135 & 93 & 148 & $-0.4192 \quad 10.20$ \\
\hline 19.4 & 184 & 115 & 158 & 148 & 151 & 105 & 144 & $-0.2013 \quad 5.35$ \\
\hline 14.5 & 179 & 114 & 131 & 124 & 136 & 95 & 136 & $-0.2333 \quad 5.30$ \\
\hline 9.1 & 135 & 103 & 144 & 115 & 132 & 87 & 113 & $-0.3289 \quad 8.65$ \\
\hline 12.6 & 139 & 111 & 146 & 136 & 126 & 109 & 129 & $-0.2858 \quad 5.75$ \\
\hline 12.2 & 142 & 110 & 153 & 130 & 135 & 91 & 141 & $-0.2172 \quad 5.80$ \\
\hline 14.5 & 170 & 114 & 142 & 140 & 158 & 111 & 117 & $-0.1758 \quad 3.25$ \\
\hline 9.5 & 134 & 112 & 159 & 133 & 168 & 111 & 84 & $-0.2261 \quad 4.50$ \\
\hline
\end{tabular}

Mean \pm SD

$111.3 \pm 3.9 \quad 146.3 \pm 8.9 \quad 129.2 \pm 14.1 \quad 141.1 \pm 14.2 \quad 100.4 \pm 9.2 \quad 126.2 \pm 20.5$

Group II (hyperinflated and bronchoconstricted)
S. J.
B. P.
D. V.
L. D.
V. T.
Mean \pm SD

Group III (bronchoconstricted)

$\begin{array}{lrr}\text { B. M. } & 18.0 & 169 \\ \text { L. P. } & 12.2 & 146 \\ \text { G. G. } & 16.3 & 171 \\ \text { S. S. } & 8.9 & 141 \\ \text { M. M. } & 16.9 & 172 \\ \text { H. M. } & 13.2 & 147 \\ \text { M. F. } & 9.5 & 147 \\ \text { T. E. } & 11.1 & 142 \\ \text { A. M. } & 10.5 & 135 \\ \text { B. F. } & 21.3 & 158\end{array}$

$\begin{array}{ll}12.2 & 149 \\ 12.3 & 156 \\ 11.3 & 142 \\ 12.3 & 155 \\ 14.1 & 152\end{array}$

110
109
118
110
109

$\begin{array}{ll}169 & 118 \\ 128 & 128 \\ 148 & 129 \\ 135 & 130 \\ 133 & 128\end{array}$

$11.2 \pm 3.8$

$142.6 \pm 16.5 \quad 126.6 \pm 4.9$

152
127
116
128
150

158
149
143
159
156

$\begin{array}{rrr}103 & -0.2172 & 5.80 \\ 125 & -0.1798 & 3.32 \\ 104 & -0.2059 & 3.15 \\ 72 & -0.2344 & 4.45 \\ 116 & -0.1457 & 2.13\end{array}$
$\begin{array}{ccc}150 & 156 & 116 \\ 134.6 \pm 15.7 & 153.0 \pm 6.8 & 104.0 \pm 20.1\end{array}$

$\begin{array}{rrr}109 & 119 & 116 \\ 105 & 124 & 120 \\ 101 & 125 & 118 \\ 113 & 115 & 118 \\ 103 & 112 & 115 \\ 98 & 114 & 118 \\ 103 & 101 & 100 \\ 102 & 116 & 110 \\ 90 & 125 & 112 \\ 84 & 102 & 89\end{array}$

117
123
150
99
132
116
128
160
93
78

139
134
132
164
153
136
226
154
145
234

$\begin{array}{rrr}121 & -0.1440 & 2.15 \\ 118 & -0.1714 & 1.55 \\ 80 & -0.1115 & 2.15 \\ 82 & -0.2227 & 1.74 \\ 93 & -0.1245 & 0.76 \\ 82 & -0.1667 & 0.30 \\ 98 & -0.1792 & 1.15 \\ 114 & -0.1633 & 1.55 \\ 106 & -0.1403 & -1.09 \\ 62 & -0.1434 & 0.65\end{array}$

Mean $\pm \mathrm{SD}$

$100.8 \pm 8.5 \quad 115.7 \pm 9.2 \quad 112.6 \pm 11.2 \quad 119.6 \pm 25.1 \quad 161.7 \pm 37.4$

$95.6 \pm 19.3$

\footnotetext{
* TLC, TGV, FRC, RV, $R_{L}$, and $C_{\mathrm{dyn}}$ are the percentage predicted for height.
} 
constriction without hyperinflation $\left(R_{L}>130 \%\right.$ predicted $=$ mean $+2 \mathrm{SD})$.

In evaluating the indices of lung distensibility $(K, \ln b)$ and bronchial distensibility $(\theta)$, the sensitivity of the indices within the three groups and the variability of the indices for a given patient and among patients in a given group (I-III) were examined and presented in Table 2. For all indices, the intrasubject variability from the repeated PV maneuvers of each patient as the relative difference $R D=\left|Z_{1}-Z_{2}\right| / A Z$ was calculated, where $Z_{1}$ and $Z_{2}$ are the values of any index $Z$ for the two PV maneuvers and $A Z$ is their average value. $M R D$ is the mean value of $R D$ within each group. The intrasubject variability of the indices is characterized for all subjects by a mean and standard deviation of the relative difference $M R D=R D / N$; $S D R D=\left(\sum(R D-M R D)^{2} / N\right)^{1 / 2}$, where $N$ is the total number of patients.

The averaged values of the two measurements for $K$ (lung distensibility) and $\theta$ (airway distensibility), expressed in SD-S (numbers of SDs from the mean) are shown in Figure 3. In order to correct for age, and hence body size, both variables are presented in SD-S. Hyperinflated patients (group I) are presented with open circles, hyperinflated and bronchoconstricted patients (group II) by closed circles, and bronchoconstricted patients without hyperinflation (group III) by triangles. There is a close relationship between $K$ and $\theta$ over the range of all three groups $(r=0.85 ; p<0.001)$.

Table 3 presents the statistical analysis: $K$ (lung distensibility) is best correlated with $R_{L}\left(r_{s}=0.63 ; p<0.001\right)$; however, it also is correlated with TGV and $C_{\text {dyn }} \theta$ is best correlated with TGV $\left(r_{s}=0.77 ; p<0.001\right)$. By the Kruskal-Wallis $H$ test, it can be demonstrated (Table 3 ) that both $K$ and $\theta$ have the potential to discriminate the three groups I-III $(p<0.001)$.

In six patients (three from group I and three from group III), the effect of a $\beta$-2-mimetic (salbutamol) was studied. Average changes in response to the inhalation of $0.5 \mathrm{mg}$ of the drug as metered aerosol are represented in Figure 4 . The higher the numerical negative value of $K$ initially is, the larger the increase of $K$ induced by the $\beta$-agonist. In contrast, after administration of bronchodilator, the bronchial distensibility represented by $\theta$ increased markedly in each subject, especially in group III. Measurements of $P_{s t L}$ at different lung volumes showed that lung elastic recoil pressure was significantly decreased at all lung volumes between 40 and $90 \%$ TLC after $\beta$-2-medication. In respect to the changes in $P_{s t L}$ after $\beta$-2-mimetics, it appears in these small groups of patients that $P_{s t L}$ at FRC was smaller in

Table 2. Means and $S D$ for intergroup sensitivity and $M R D$, as well as means and $S D$ for intrasubject variability.

\begin{tabular}{|c|c|c|c|c|}
\hline \multirow[b]{2}{*}{$n$} & \multicolumn{3}{|c|}{ Sensitivity } & \multirow{2}{*}{$\frac{\text { Variability (\%) }}{\text { Means SD }}$} \\
\hline & Means & SD & $M R D$ & \\
\hline \multicolumn{5}{|l|}{$K$} \\
\hline I. & -0.2802 & 0.077 & 0.182 & \\
\hline II. & -0.1966 & 0.034 & 0.155 & \\
\hline III. & -0.1512 & 0.034 & 0.176 & \\
\hline
\end{tabular}

$\begin{array}{rlll}\begin{array}{l}\text { All } \\ \ln b\end{array} & & & \\ \text { I. } & 2.20 & 0.512 & 0.147 \\ \text { II. } & 1.24 & 0.514 & 0.105 \\ \text { III. } & 0.81 & 0.441 & 0.197\end{array}$

\begin{tabular}{|c|c|c|c|}
\hline $\begin{array}{l}\text { All } \\
\theta\end{array}$ & & & \\
\hline I. & 6.42 & 2.451 & 0.103 \\
\hline II. & 3.86 & 1.136 & 0.165 \\
\hline III. & 1.42 & 0.979 & 0.105 \\
\hline
\end{tabular}

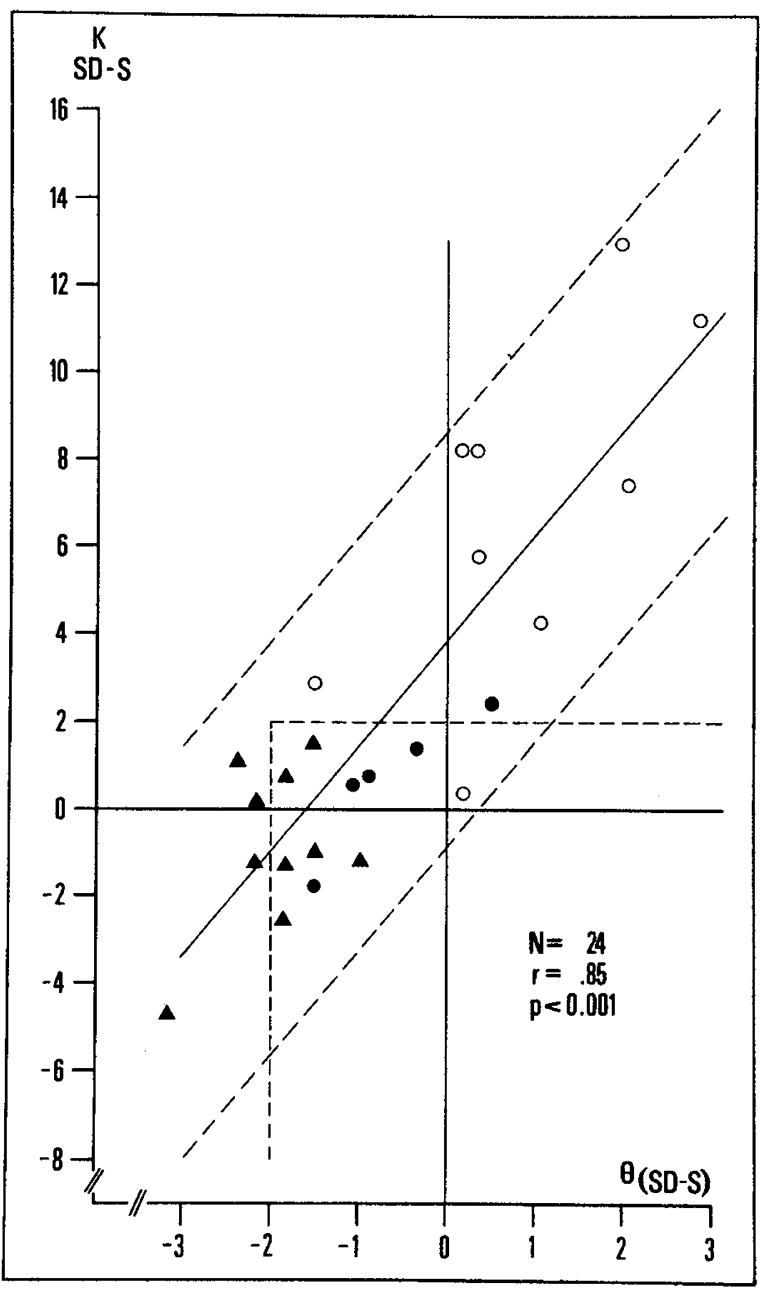

Fig. 3. Relationship between $\theta$ (slope of the $P_{s L L}-G_{L}$ plot) as index of airway distensibility and $K$ (exponential factor of the PV curve) as index of lung distensibility, both presented in standard deviations scores (SD$\mathrm{S}=$ number of $\mathrm{SDs}$ from the mean) (O: hyperinflated patients, group I; -: patients with hyperinflation and bronchoconstriction, group II; $\mathbf{\Delta}$ : patients with bronchoconstriction without hyperinflation, group III). Rectangular lines $(-2 \mathrm{SD} \theta, 2 \mathrm{SD} K)=2 \mathrm{SD}$ of $\theta, K$, respectively.

Table 3. Correlations between $K$ and $\theta$ and different lung function parameters (Spearman rank correlation test)*

\begin{tabular}{lcc}
\hline & \multicolumn{2}{c}{$r_{s}$} \\
\cline { 2 - 3 } & $K$ & $\theta$ \\
\hline TGV & $0.57 \dagger$ & $0.77 \ddagger$ \\
$R_{L}$ & $0.63 \ddagger$ & $0.70 \ddagger$ \\
$C_{\text {dyn }}$ & $0.59 \ddagger$ & $0.52 \dagger$ \\
Kruskal-Wallis $H$ test $^{*}$ & $15.66 \ddagger$ & $16.59 \ddagger$ \\
$\hat{H}$ & & \\
$\chi_{2,0.001}^{2}=13.82$ & \\
\hline
\end{tabular}

* Evaluation of the distinction of groups I-III, due to $K$ and $\theta$. $\left(r_{s}\right.$, Spearman correlation coefficient; $H$, variance of all rank sums).

$\dagger p<0.005$.

$\ddagger p<0.001$.

patients of group I (22.1\%) than the decrease in $P_{s t L}$ at $80 \%$ TLC $(26.5 \%)$, whereas the decrease in $P_{s t L}$ at FRC in patients of group III was clearly higher $(21.7 \%)$ than the decrease in $P_{s L L}$ at $80 \%$ TLC (14.2\%).

\section{DISCUSSION}

The present study shows that sigmoid exponential modelfitting of static PV curves can be applied to PV curves of 


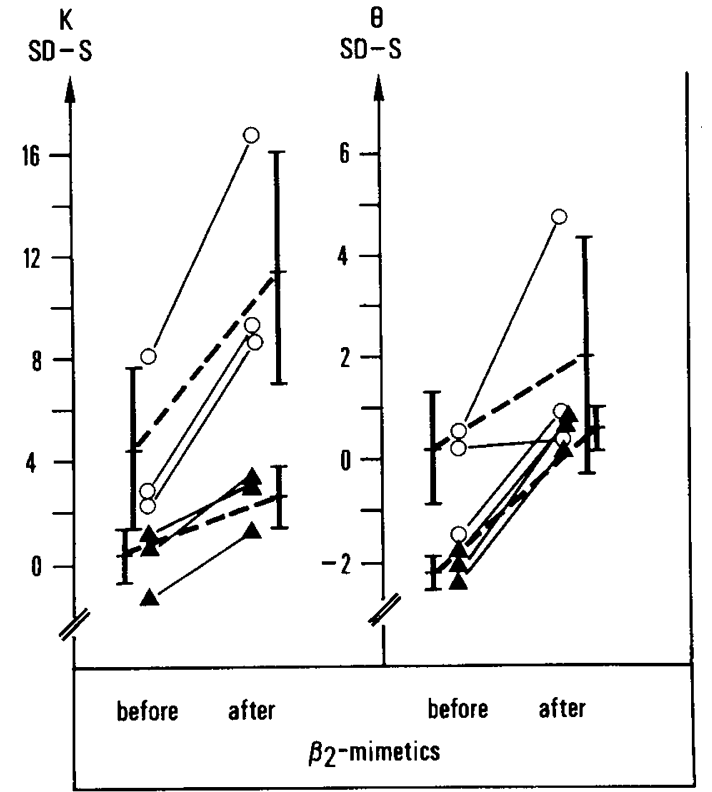

Fig. 4. Influence of a $\beta$-2-agonist (salbutamol) inhaled as metered aerosol on the $K$ values (lung distensibility) and the slope $\theta$ (airway distensibility), both presented in standard deviations scores (SD-S = number of SDs from the mean). O: hyperinflated patients, group I; $\boldsymbol{\Delta}$ : bronchoconstricted patients, group III.

asthmatic children. In this context, the shape constant $K$ can be thought to be an index of lung distensibility. Evaluating the forces distending the airways, $\theta$, the slope of the $P_{s L L}-G_{L}$ plot features an index of the dynamic behavior of the conducting airways and consequently is an index of airway distensibility. This study shows that there is a linear relationship between $K$ and $\theta$, revealing that lung distensibility is closely related with airway distensibility (Fig. 3).

However, before considering the implication in respect to the clinical relevance of this functional feature, some aspects of measurements and their significance have to be pointed out. The "static" pressures are in fact values taken at instants of zero flow during quiet breathing; hence, the values are similar to dynamic compliance measurements, but performed for a substantial range of lung volume (45-90\% TLC). In a previous paper, we showed that there is no frequency dependence, at least if the "stepwise inflation/deflation technique" is applied (24). It must be assumed that the end-expiratory pressure points fall within the area of the hysteresis of full static inflational and deflational limbs of measurements performed by the usual technique. Consequently, our technique cannot show the phenomenon of hysteresis, and the results presented are not easily comparable with other studies. PV characteristics are influenced by the number of functioning alveolar units contributing to the shape of the PV curve. This fact has to be considered especially if lungs with different alveolar size are investigated. In addition, the determination of $K$ is influenced by the presence or absence of volume of trapped gas, and alveolar recruitment at higher lung volumes has to be considered, a standard which is fulfilled, since lung volumes are measured and introduced in the computation of the PV curve fitting in absolute terms (see "Materials and Methods"). In the present study, the different lung size of the growing child has been taken into acount in as far as data have been based on values predicted normal. The values found in asthmatic children, therefore, have been expressed either in per cent predicted or standard deviation scores (SD-S = number of SDs from the mean).

The exponential PV curve analysis and the corresponding relationship with the $P_{s L}-G_{L}$ plot allow the distinction into two types of functional derangements, one concerning lung distensibility and the other airway distensibility. Different authors dem- onstrated in studies of excised postmortem lungs with morphometric changes that PV behavior enables the distinction between different stages of emphysema $(18,32)$. The shape constant $K$ as a discriminating index in the detection of emphysema patients was established. Pulmonary emphysema by definition is a morphologic diagnosis and, therefore, can only be truly identified by histological examination of the lungs. We have no such findings. On the other hand, it is recognized that in adults there are some asthmatic patients with hyperinflation and high numerical negative $K$ values. They have additionally a certain loss of elastic recoil and consequently increased lung compliance. The question arises whether children with hyperinflation and very high numerical negative $K$ values are not patients presenting pre- stages of such adult asthmatics presumably with already enlarged airspaces.

It was demonstrated several years ago that only the $P_{s t L}-G_{L}$ slope represents adequately the flow-resistive behavior of the lungs $(5,25)$. In contrast to the static recoil airway conductance $\left(P_{s t L}-G_{a w}\right)$ relationship investigated by several authors $(16,25)$, the static recoil lung conductance plot includes lung tissue resistance $(2,3)$. This component is more dominant the younger the subject is and the higher the subject's end-expiratory level approaches the full inspiratory position (2). If interstitial changes of the lung are suspected and lung conductance is measured, such values are in comparison with normal subjects decreased even at FRC (1). In contrast, static recoil airway conductance curves may be in the range of normal (16). There are three contributing factors determining the differences of $\theta$, the slope of the $P_{s t L}-G_{L}$ plots. (a) At constant mean flow rate and FRC, the lung tissue resistance increases with increasing tidal volume (3). (b) Lung tissue resistance is considerably higher in subjects with small lung volumes and low compliances than in large and highly compliant lungs (2). (c) Lung tissue resistance increases progressively when breaths are taken on increasing inspiratory level, i.e. where compliance is reduced and hence transpulmonary pressure amplitudes (pressure difference between end-inspiratory and endexpiratory points of a breath) begin to be larger $(2,3)$. Therefore, differences in the $P_{s t L}-G_{L}$ relationship can serve as a second discriminating element in the approach to separate different functional groups of asthmatic children. Consequently, patients of group III presenting reduced airway distensibility are assumed to suffer from a flow-independent resistive pulmonary defect due to an alteration of the nonideal elastic behavior of the lung tissue with increased work per breath and mechanical energy loss dissipated as heat.

The influence of $\beta$-2-agonists on PV curve characteristics has only been reported on the basis of $P_{s L L}$ changes at different lung volumes in adults $(10)$. Our findings of decreased $P_{s L L}$ especially for higher lung volumes, represented by increased $K$ values, are in agreement with the results of De Troyer et al. (10) showing that healthy subjects after administration of a $\beta$-2-agonist decrease lung elastic recoil for all lung volumes. The findings of increasing $K$ in hyperinflated patients (group I) after $\beta$-2-mimetics are in contrast to observations of Colebatch et al. (8) showing a decrease of $K$ in adult asthmatics after $\beta$-2-mimetics. One explanation can be found in the manner the PV data have been computed. Whereas Colebatch's curve fitting is restricted to the upper lung volume ranges ( $>50 \%$ TLC), avoiding the influence of airway closing and airway opening, our curve-fitting model takes into account the whole range of inspiratory capacity (FRC until $90 \%$ TLC). This approach therefore may be affected by changes in the airway dynamics. Thus, the increase of $K$ after $\beta$ 2 -mimetics in our study may well be the effect of better airspace ventilation.

According to the network model of pulmonary elastic behavior described by Mead et al. (27), it may be assumed that elastic recoil is altered by changes in the tensile forces per unit area transmitted by each element. However, although tissue elements provide a degree of structural rigidity for alveolar septa, and facilitate the transmission of forces between contiguous air spaces 
(interdependence phenomena), findings of Haber et al. (19) indicate that the density of surface forces is more relevant than the density of tissue elements in determining lung recoil. One other hypothetical explanation could be found by attributing changes in the PV characteristics due to $\beta$-2-agonists to changes in the alveolar duct smooth muscle tone. This suggests that $\beta-2-$ agonists produce dilation of terminal lung units by relaxing smooth muscles in the alveolar ducts or elsewhere and the marked increase in $K$ could be explained as consistent with the findings of Haber et al. (19), demonstrating that in different species, differences in lung distensibility (defined by $K$ ) are directly related to the size of air spaces.

In conclusion, the study shows that even in the "symptomfree" interval marked functional abnormalities may be present in asthmatic children. There must be a distinction between increase of lung distensibility and impeded airway function. The influence of $\beta$-2-mimetics to the latter abnormality is favorable. In contrast, $\beta$-2-mimetics seem to increase even more the lung distensibility of asthmatic children whose lungs are already too compliant, a rather undesired effect. However, this latter observation is controversial and, moreover, the time course of this effect is not known. Further studies are needed in order to define the efficiency of $\beta$-2-agonists, especially in hyperinflated asthmatics.

Acknowledgments. The authors gratefully acknowledge Prof. S. Godfrey for reviewing the manuscript and useful criticism, Ms. I. Glaser and Mr. R. Stucki for graphical representation, and Mrs. S. Lerch for secretarial work.

\section{REFERENCES}

1. Bachofen H, Scherrer M 1967 Lung tissue resistance in diffuse interstitial pulmonary fibrosis. J Clin Invest $46: 133$

2. Bachofen H, Duc G 1968 Lung tissue resistance in healthy children. Pediatr Res 2:119

3. Bachofen H 1968 Lung tissue resistance and pulmonary hysteresis. J Appl Physiol 24:296

4. Butler J, Caro CG, Alcala R, DuBois AB 1960 Physiological factors affecting airway resistance in normal subjects and in patients with obstructive respiratory disease. $\mathrm{J}$ Clin Invest 39:584

5. Colebatch HJH, Finucane KE, Smith MM 1973 Pulmonary conductance and elastic recoil relationships in asthma and emphysema. J Appl Physiol 34:143

6. Colebatch HJH, Ng CKY, Nikov N 1979 Use of an exponential function for elastic recoil. J Appl Physiol 46:387

7. Colebatch HJH, Greaves IA, Ng CKY 1979 Exponential analysis of elastic recoil and aging in healthy males and females. $J$ Appl Physiol 47:683

8. Colebatch HJH, Greaves IA, Ng CKY 1979 Pulmonary mechanics in diagnosis. In: De Kock MA, Nadel JA, Lewis CM (eds) Mechanisms of Airways Obstruction in Human Respiratory Disease. Balkema, Rotterdam, pp 2547

9. Cooper DM, Crutz E, Levison H 1977 Occult pulmonary abnormalities in asymptomatic children. Chest 71:361

10. De Troyer A, Yernault JC, Rodenstein D 1978 Influence of beta-2-agonist aerosol on pressure-volume characteristics of the lung. Am Rev Respir Dis 118:987
11. DuBois AB, Botelho SY, Bedell GN, Marshall R, Comroe JH 1956 A rapid plethysmographic method for measuring thoracic gas volume: a comparison with a nitrogen washout method for measuring functional residual capacity in normal subjects. J Clin Invest 35:322

12. Geubelle F, Senterre J 1963 Une nouvelle technique plethysmographique corporelle pour la mesure de la resistance des voies respiratoires chez l'enfant. Arch Intern Physiol Biochem 71:107

13. Geubelle F, Breny H 1969 Volumes pulmonaire de filles et de garcons sains, ages de 5 a 16 ans. Poumon Coeur 25:1051

14. Geubelle F, Vavrova V, Lambrechts 1969 Mesure de la pression intrathoracic chez l'enfant. Poumon Coeur 25:1075

15. Guebelle F, Vavrova V 1969 Compliance et resistance pulmonaires au debit aerien chez l'enfant sain. Poumon Coeur 25:1085

16. Gibson GJ, Pride NB 1977 Pulmonary mechanics in fibrosing alveolitis. Am Rev Respir Dis 116:637

17. Gibson GJ, Pride NB, Davis J, Schroter RC 1979 Exponential description of the static pressure-volume curve of normal and diseased lungs. Am Rev Respir Dis 120:799

18. Greaves IA, Colebatch HJH 1980 Elastic behavior and structure of normal and emphysematous lungs post mortem. Am Rev Respir Dis 121:127

19. Haber PS, Colebatch HJH, Ng CKY, Greaves IA 1983 Alveolar size as a determinant of pulmonary distensibility in mammalian lungs. J Appl Physiol $54: 837$

20. Knudson R, Kaltenborn W 1981 Evaluation of lung elastic recoil by exponential curve analysis. Respir Physiol 46:29

21. Kraemer R, Duquenne D, Mossay C, Geubelle F 1981 Mode of action of bronchodilating drugs on histamine-induced broncho-constriction in asthmatic children. Pediatr Res 15:1433

22. Kraemer R, Herrygers M, Geubelle F 1982 Characteristics of static recoil lung conductance relationship in asthmatic children. Prog Respir Res 17:87

23. Kraemer R, Schaad UB, Meister B, Rossi E 1983 Reversibility of lung function abnormalities in children with perennial asthma. J Pediatr 102:347

24. Kraemer R, Wiese G, Albertini M, Baghriche M, Geubelle F 1983 Elastic behavior of the lungs in healthy children determined by means of an exponential function. Respir Physiol 52:229

25. Leaver DG, Tattersfield AE, Pride NB 1973 Contribution of loss of lung recoil and of enhanced airway collapsibility to the airflow obstruction of chronic bronchitis and emphysema. J Clin Invest 52:2117

26. Mead J, Turner JM, Macklem PT, Little JB 1967 Significance of the relationship between lung recoil and maximal expiratory flow. J Appl Physiol 22:95

27. Mead J Takishima T, Leith D 1970 Stress distribution in the lungs: a model of pulmonary elasticity. J Appl Physiol 28:596

28. Milic-Emili J, Mead J, Turner JM, Glauser EM 1964 Improved technique for estimating pleural pressure from esophageal ballons. J Appl Physiol 19:207

29. Murphy BG, Engel LA 1978 Models of the pressure-volume relationship of the human lung. Respir Physiol 32:183

30. Niewoehner DE, Kleinermann J, Liotta I 1975 Elastic behavior of postmortem human lungs. Effects of aging and mild emphysema. J Appl Physiol 39:943

31. Paiva M, Yernault IC, Van Eerdeweghe P, Englert M 1975 A sigmoid model of the static volume-pressure curve of human lung. Respir Physiol 23:317

32. Pare PD, Brooks LA, Bates J, Lawson LM, Nelems JMB, Wright JL, Hogg JC 1982 Exponential analysis of the lung pressure-volume curve as a predictor of pulmonary emphysema. Am Rev Respir Dis 126:54

33. Pengelly LD 1977 Curve fitting analysis of pressure-volume characteristics of the lungs. J Appl Physiol 42:111

34. Pride NB, Permutt S, Riley RL, Bromberger-Barnea B 1967 Determinants of maximal expiratory flow from the lungs. J Appl Physiol 23:646

35. Salazar E, Knowles JH 1964 An analysis of pressure-volume characteristics of the lungs. J Appl Physiol 19:97

36. Schroter RC 1980 Quantitative comparison of mammalian lung pressurevolume curves. Respir Physiol 42:10I

37. Zamel N, Hogg J, Gelb A 1976 Mechanisms of maximum expiratory flow limitation in clinically unsuspected emphysema and obstruction of the peripheral airways. Am Rev Respir Dis 113:337 